\title{
Mide Kanseri'nde Erken Tanı Hayat Kurtarır
}

\section{Early Diagnosis in Stomach Cancer Saves Lives}

\author{
Tahir Buran ${ }^{1}$, Mustafa Şahin ${ }^{2}$ \\ 'Celal Bayar Üniversitesi Tıp Fakültesi İç Hastalıkları Kliniği Gastroenteroloji Bölümü \\ ${ }^{2}$ Celal Bayar Üniversitesi Tıp Fakültesi İç Hastalıkları Kliniği \\ e-mail: tahir.buran@hotmail.com,mstfaashn@gmail.com \\ ORCID; 0000-0002-8077-2582 \\ ORCID; 0000-0002-2324-7052 \\ *Sorumlu yazar/Corresponding Author: Tahir Buran \\ Gönderim Tarihi / Received: 24.11.2020 \\ Kabul Tarihi / Accepted: 05.12.2020 \\ DOI: $10.34087 /$ cbusbed.783811
}

\begin{abstract}
Mide kanseri, dünyada en sık görülen 5 kanserden biridir. Görülme sıklığı dünya genelinde büyük coğrafi farklılıklar göstermektedir. Mide Kanseri Japonya'da kanserden ölümlerin başlıca nedenlerindendir, bu ülkede erken tanı için endoskopideki gelişmelerle birlikte ulusal tarama programları uygulanarak mide kanserine erken tanı konmaya başlanmıştır. Mide kanseri sebepleri arasında; Helikobakter pilori, atrofik gastrit, intestinal metaplazi ve displazi, aşırı tuzlu gıda ile beslenme, mide ameliyatı geçirme, pernisiyöz anemi ve genetik yatkınlık gösterilmektedir. Mide kanserlerinin \%90'dan fazlası adeno kanser tipinde olup genellikle tanı anında ileri evrededir. 5 yıllık yaşam bu grupta \%15-20'dir. Erken mide kanserinde endoskopik olarak submukozal rezeksiyon yapılarak kür sağlanabilmektedir. Eğer evre 2 ve üzeri mide kanseri ise geç kabul edilmektedir. Geç mide kanserinde hastalı̆̆ın durumuna göre cerrahi rezeksiyon, kemoterapi veya radyoterapi yapılabilmektedir.
\end{abstract}

Anahtar Kelimeler: Erken evre mide kanseri, Mide kanseri, evreleme

\begin{abstract}
Stomach cancer is one of the 5 most common cancers in the world. Its incidence varies widely across the world. Stomach Cancer is one of the main causes of cancer deaths in Japan, with the developments in endoscopy for early diagnosis in this country, early diagnosis of gastric cancer has been started by applying national screening programs. Among the causes of stomach cancer: Helicobacter pylori, atrophic gastritis, intestinal metaplasia and dysplasia, eating with high-salt food and genetic predisposition. More than $90 \%$ of stomach cancers are of the adenocarcinoma type and are usually advanced at the time of diagnosis. 5-year life is $15-20 \%$ in this group. Early gastric cancer can be cured by endoscopic submucosal resection. If it is stage 2 and above stomach cancer, it is considered late. In late stomach cancer, surgical resection, chemotherapy or radiotherapy can be performed depending on the condition of the disease.
\end{abstract}

Key Words: Early stage gastric cancer, Stomach cancer, Staging.

\footnotetext{
1. Giriş

Gastrik kanser; Dünyada görülme sıklığı bakımından 5 . Sırada ve kansere bağlı ölümlerde 3. Sırada olan önemli sağlık problemlerinden biridir. Görülme sıklığı dünya genelinde büyük coğrafi farklılıklar göstermektedir. Mide kanseri Amerika Birleşik Devletleri ve İngiltere gibi gelişmiş ülkelerde en düşük oranlardayken (Yaklaşık 10/100000), Japonya, Çin ve Güney Amerika gibi bölgelerde daha yüksek oranlarda görülmektedir(5080/100000)[1-3].
}

Mide Kanseri Japonya'da kanserden ölümlerin başlıca nedenlerindendir, bu ülkede erken tanı için endoskopideki gelişmelerle birlikte ulusal tarama programları uygulanarak mide kanserine erken tanı konmaya başlanmıştır[4-6]. Taramadaki yaygınlık ve erken teşhis ile Japonya'daki büyük merkezlerde tedavi edilen mide kanserlerinin yaklaşık yarısına erken mide kanseri(EMK) tanıs1 konmaktadır[7]. Mide kanseri sebepleri arasında: Helikobakter pilori, atrofik gastrit, 
intestinal metaplazi ve displazi, aşırı tuzlu gıda ile beslenme ve genetik yatkınlık gösterilmektedir.

\section{Makroskopik Özellikler ve Evrelendirme}

Mide kanserinin makroskopik sinıflandırması, Borrmann tarafından yapılmış olan tümörün morfolojik özelliklerine dayanır. Borrmann tümör sınıflamasında; Tip 1; polipoid Tümörler, Tip 2; sınırlı çökük tümörler, Tip 3; ülsere tümörler, tip 4; diffüz infiltre tümörler olarak 4 tipe ayrılır. Mide kanserinin 2 temel histopatolojik varyantları Lauren tarafindan; intestinal tip ve diffüz tip olarak tanımlanmıştır[8,9].

Tablo 1. Amerikan Kanser Komitesinin Mide kanserleri için TNM evreleme sistemi

\author{
Tümör (T) evresi \\ Tx: Primer tümör değerlendirilemez \\ T0: Primer tümör için kanıt yok \\ T1s: Karsinoma in situ; İntraepitelial tümör(Lamina \\ propriada invazyon yok) \\ T1: Tümör mukoza veya submukozayla sınırlıdır \\ T1a: Tümör lamina propria veya muskularis mukozayı \\ tutmuştur \\ T1b: Tümör submukozayı tutmuştur \\ T2: Tümör muskularis propriyayı tutmuştur \\ T3: Tümör subserozal bağ dokusunu tutmuştur ancak \\ visseral periton(seroza) ve çevre dokular sağlamdır \\ T4: Tümör visseral periton ve komsu dokulara \\ yayılmıştır \\ T4a: Tümör visseral peritonu tutmuştur \\ T4b: Tümör komşu dokuları tutmuştur
}

\section{Nodal (N) Evre}

Nx: Bölgesel lenf nodları değerlendirilemez

N0: Bölgesel lenf nodları tutulumu yok

N1: 1-2 bölgesel lenf nodu tutulumu

N2: 3-6 bölgesel lenf nodu tutulumu

N3: $>7$ bölgesel lenf nodu tutulumu

N3a: 7-15 bölgesel lenf nodu tutulumu

N3b: $>16$ bölgesel lenf nodu tutulumu

\begin{tabular}{l} 
Uzak Metastaz $(\mathbf{M})$ \\
\hline Mx: Uzak metastaz değerlendirilemez \\
M0: Uzak metastaz yok \\
M1: Uzak metastaz var(ör. karaciğer metastazı, \\
periton metastazı)
\end{tabular}

\footnotetext{
Evreleme

Evre 0: Tis N0 M0

Evre 1A: T1 N0 M0

Evre 1B: T1 N1 M0, T2a/b N0 M0

Evre 2A: T1 N2 M0, T2a/b N1 M0, T3 N0 M0

Evre 2B: T1 N3 M0, T2 N2 M0, T3 N1 M0, T4a N0

M0

Evre 3A: T4a N1 M0, T3 N2 M0, T2 N3 M0

Evre 3B: T3 N3 M0, T4a N2 M0, T4b N0 M0, T4b N1 M0

Evre 4: Herhangi bir T, Herhangi bir N M1
}

Kanserlerin doğru evrelenmesi önemlidir, çünkü prognoz hakkında bilgi sağlar ve tedaviye yön verilebilmektedir. Tablo-1 de mide kanserinde kullanılan tümör, lenf nodu ve metastaz(TNM) sinıflamasını göstermektedir. Evrelemede endoskopik ultrasonografi (EUS) yardımıyla malign görünümdeki lenf nodlarından iğne aspirasyonu yapılır ve bu sayede $\mathrm{N}$ evrelemesinde tanısal doğruluk artar.

EUS, mide kanserlerinin invazyon derinliğini değerlendirmek için mevcut en güvenilir cerrahi olmayan yöntemdir. EUS Avrupa tıbbi onkoloji derneği (ESMO) tarafindan radyografik olarak metastatik (M1) hastalık kanıtı olmayan ve potansiyel olarak operabl hastalığ olan mide kanserli tüm hastaların tedavi öncesi değerlendirmesi için önerilmektedir[10].

Nakamura ve arkadaşları ise mide kanserlerini iyi diferansiye ve kötü diferansiye olmak üzere iki tip olarak tanımlamışlardır[11]. İntestinal veya iyi diferansiye tip; glandüler ve solid yapılar kadar tübüler yapıların komponentlerini içerir, oysa diffüz veya kötü diferansiye tipte, tek hücreler veya zayıf şekilde bağlı hücre kümeleri şeklinde mide duvarını infiltre eder. Intestinal tip mide kanseri kronik atrofik gastrit, intestinal metaplaziyle birlikte kronik atrofik gastrit, displazi veya invaziv karsinom gibi öncü lezyonlardan gelişebilir, oysa taşl1 yüzük hücreli karsinom gibi diffüz mide karsinomları intestinal metaplaziden bağımsız şekilde gelişir[12,13]. Mide kanserlerinin \%90'dan fazlası adenokanser tipinde olup genellikle tanı anında ileri evrededir. 5 yıllık yaşam bu grupta \%15-20'dir. Eğer kanser midede sinırlı ise 5 yıllık yaşam \%55'lere çıkar.

\section{Erken mide kanseri (EMK) :}

Erken mide kanseri, Japon mide kanseri araştırma cemiyeti tarafindan, 1963 y1lında bölgesel lenf nodu tutulumuna bakılmaksızın mukoza veya submukozaya sınırlı mide adenokarsinomu (T1Nx) şeklinde tanımlanmıştır[7]. Erken mide kanseri ilk yapılan Borrmann sinıflamasında yoktur fakat günümüzde Japon mide kanseri sinıflandırmasında Tip 0 olarak siniflandirilır[8].

Japon sinıflandırması EMK' yi 3 tipe ayırır:

Tip1; protrüde(dışarı doğru çıkıntılı) tip

Tip 2; süperfisial(yüzeyel) tip,

Tip 3; çukur tip.

Tip 1 tümörler sıklıkla papiller yapılar arasında çatlakları olan düzensiz yüzeyli, uzun, nodüler veya polipoid lezyonlardır.

Tip 2 lezyonlar üç alt tipe ayrılmıştır.

Tip 2a-süperfisial, hafifçe mukozadan kabarık tip, mukoza kalınlığı 5 mm’ye kadar hafifçe kabarık olmuştur.

Tip 2 b lezyonlar; yüzeyel düz tip, yaklaşık olarak çevre mukoza ile aynı seviyededir,

Tip 2c lezyonlar; yüzeyel, hafifçe çökük tiptir. Tip 2c lezyonlar en sık ve klinik tanı açısından en önemli olan lezyonlardir. 
Tip 3 lezyonlar, ülser çevresi boyunca kanser dokusu tarafından dar bir yarık şeklinde çevrelenmiş, derin, ülser benzeri bir çöküntü ile karakterizedir. Lezyon benign bir ülseri taklit edebilir, saf tip 3 lezyonlar nadirdir ve erken mide kanserinin $\% 2$ sinden azından sorumludur.

Erken mide kanserinin karışık tipleri iki veya daha fazla temel makroskopik tipin aynı anda tek lezyonda bulunmasıyla meydana gelir. Genel olarak, histolojik tipten bağımsız olarak, önce daha büyük alan kaplayan tip rapor edilir.

Toplum taraması mide kanseri insidansının yüksek olduğu(50-80/100000) Japonya gibi ülkelerde önerilebilir [5,6].

Endoskopi erken mide kanserinin saptanmasında en değerli araçtır. Endoskopi; erken mide kanseri insidansı düşük olan ülkelerde semptomatik hastaların taranmasında, mide kanserinin erken tanınması ve tedavi edilmesinde oldukça etkili aletlerdir. Ayrıca endoskopi ile şüphelenilen lezyonlardan alınan biyopsi ile intramukozal adenokarsinom gelse dahi bu erken mide kanseri anlamına gelmez, erken mide kanser tanısı için "'endoskopik ultrasonografi" yapılarak tanı konulup evreleme yapilmalidir[10].

\section{Klinik Bulgular}

Mide kanserli hastalarda klinik olarak: karında şişkinlik, karın ağrısı, erken doyma, bulantı, pilor ağzını tutan tümörlerde kusma ve kilo kaybı, gizli ya da aşikar kanamaya bağlı kansızlık ve halsizlik, özellikle kardiya tutulumu mevcut ise yutma güçlüğü görülebilir. Mide tümörü ileri evre ise metastaz bulguları ortaya çıkar.

Karaciğer metastazlarında sarılık, periton tutulumu varsa asit görülebilir. Ayrıca lenf bezleri metastazları, özellikle sol supraklavikuler lenf bezleri(Virchow nodülü), sol koltuk altı lenf bezi tutulumu(İrish nodülü) göbek etrafında tutulum(Sister mary joseph nodülü) ve rektum etrafinda tutulum(Blummer rafi) ve over tutulumu(Krukenberg tümörü) geç dönem bulgulardır. Mide kanserlerinin çoğu sporadik olmasına rağmen, ailelerde kümelenme vakaların yaklaşık yüzde 10'unda görülür. Ailede yaş farketmeksizin en az biri doğrulanmış mide kanseri öyküsü bulunması durumunda, aile geçmişine bakılmaksızın 40 yaş altında teşhis edilen diffüz mide kanseri olması durumunda veya en az biri 50 yaş altında tanı almış ailede diffüz mide kanseri ve lobüler meme kanseri öyküsü olması durumunda genetik zemin düşünülmelidir [14-17].

\section{Tanı}

Endoskopi altın standarttır. Deneyimli ellerde \%90 üzerinde doğru tanı konmaktadır. Mide duodenum grafilerinin tanı değeri \%50'leri geçmemektedir. Ayrıca Ultrasonografide kitle büyük ise tanıya katkı sağlayabilir yine bilgisayarlı tomografi ve manyetik rezonans görüntüleme özellikle metastazlarda yararlı olabilir. Endoskopik ultrasonografi ile erken mide kanseri tanısı ve evelemesi yap1labilmektedir [1-17].

\section{Tedavi}

Amaç mide kanserini erken tespit etmek olmalıdır.
Erken mide kanserinde endoskopik olarak submukozal rezeksiyon yapılarak kür sağlanabilmektedir. Eğer evre 2 ve üzeri mide kanseri ise geç kabul edilmektedir [a]. Geç mide kanserinde hastalığın durumuna göre cerrahi rezeksiyon, kemoterapi yada radyoterapi yapılabilmektedir. Ayrıca hastalarda Helikobakter pilori mevcut ise mutlaka eradike edilmeli, 1. Derecede yakınlarında mide kanseri olan bireyler endoskopik olarak yakından takip edilmelidir.

\section{Sonuç}

Mide kanserinde erken tanı prognozda çok önemlidir. EMK da yüksek oranda kür sağlandığı için özellikle endoskopi yapılan hastalarda EMK açısından dikkatlice yapılması ve şüpheli alanlardan biyopsi alınmalıdır.

\section{Referanslar}

1. Ferlay, J, Soerjomataram, I, Dikshit, R, Eser, S, Mathers, C, Rebelo, $\mathrm{M}$ et al, Cancer incidence and mortality worldwide: Sources, methods and major patterns in globacan 2012, International Journal of Cancer, 2015, 136, 359-86.

2.Şenateş, E, İnce, A.T, Erken mide kanseri, Güncel gastroenteroloji, 2011, 161-165.

3.Parkin, D.M, Bray, F.I, Devesa, S.S, Cancer burden in the year 2000, The global picture, European Journal of Cancer, 2001, 37 Suppl 8, 4-66.

4. Hirschowitz, B.I, Endoscopy--40 years since fiber optics, Any light at the end of the tunnel? Digestive Surgery, 2000, 17(2), 115-117.

5. Hisamichi, S, Sugawara, N, Mass screening for gastric cancer by Xray examination, Japanese Journal of Clinical Oncology, 1984, 14(2), 211-223.

6. Shiratori, Y, Nakagawa, S, Kikuchi, A et al, Significance of a gastric mass screening survey, American Journal of Gastroenteroly. 1985 , 80(11), 831-834.

7. Ono, H, Kondo, H, Gotoda, T, et al, Endoscopic mucosal resection for treatment of early gastric cancer, Gut, 2001, 48(2), 225-229.

8. Japanese Gastric Cancer Association, Japanese Classification of Gastric Carcinoma, 2nd English Edition, Gastric Cancer, 1998, 1(1), 10-24.

9. Lauren, P, The two histological main types of gastric carcinoma: diffuse and so-called intestinal-type carcinoma, An attempt at a histoclinical classification, Acta Pathologica et Microbiologica Scandinavica, 1965, 64, 31-49.

10. Smyth, E.C, Verheij, M, Allum, W, et al, Gastric cancer: ESMO Clinical Practice Guidelines for diagnosis, treatment and followup. Annals of Oncology, 2016, 27(suppl 5), v38-v49. doi:10.1093/annonc/mdw350

11. Nakamura, K, Sugano, H, Takagi, K, Kumakura, K, Gan No Rinsho( Japanese Journal of Cancer Clinics), 1969, 15(7), 627-647.

12. Correa, P, Haenszel, W, Cuello, C, Tannenbaum, S, Archer, M.A, model for gastric cancer epidemiology, Lancet, 1975, 2(7924), 58-60.

13. Carneiro, F, Huntsman, D.G, Smyrk, T.C, et al, Model of the early development of diffuse gastric cancer in E-cadherin mutation carriers and its implications for patient screening, Journal of Pathology, 2004, 203(2), 681-687.

14. Oliveira, C, Pinheiro, H, Figueiredo, J, Seruca, R, Carneiro, F Familial gastric cancer: genetic susceptibility, pathology, and implications for management, Lancet Oncology, 2015, 16(2), 60-70.

15. van der Post, R.S, Vogelaar, I.P, Carneiro, F, et al. Hereditary diffuse gastric cancer: updated clinical guidelines with an emphasis on germline CDH1 mutation carriers. Journal of Medical Genetics. 2015;52(6):361-374.

16. Stjepanovic N, Moreira L, Carneiro F et al, Hereditary gastrointestinal cancers: ESMO Clinical Practice Guidelines for diagnosis, treatment and follow-up, Annals of Oncology, 2019, 30(10), 1558-1571.

17. Yoshida, N, Doyama, H, Yano T et al, Early gastric cancer detection in high-risk patients: a multicentre randomised controlled trial on the effect of second-generation narrow band imaging, Gut, 2020, 0, 1-9. doi:10.1136/gutjnl-2019-319631 
http://edergi.cbu.edu.tr/ojs/index.php/cbusbed isimli yazarın CBU-SBED başlıklı eseri bu Creative Commons Alıntı-Gayriticari4.0 Uluslararası Lisansı ile lisanslanmıştır.

(c) (†) \&) 